\title{
Sense of place and certainty in uncertain socioeconomic conditions: Contributions of local cuisine to culinary tourism
}

\begin{abstract}
This study examines the extent to which local cuisine helps shape a sense of place and its contribution to adapting to uncertain socioeconomic conditions. By adopting entrepreneurial action theory, and through its associations with the findings, the study proposes a framework illustrating the significance of the above themes in the context of Peru's gastronomy. The data are based on interviews with 14 restaurant owners-managers operating in the city of Lima, Peru. This approach was further complemented by on-site observations, and by archival data of businesses (company websites, printed information). The findings reveal alignment with both stages of entrepreneurial action, predominantly through opportunity attention, which emphasises recognising and acting upon opportunities in general. This stage became apparent through comments underlining the significance of local gastronomy in contributing to sense of place. Similarly, opportunity attention arose in comments highlighting the potential of local gastronomy as a tool for socioeconomic development.
\end{abstract}

Keywords: Gastronomy, culinary tourism, sense of place, certainty, uncertainty, entrepreneurial action theory, Peru

\section{Introduction}

Various authors (Arce, 2005; Kelly, 2003; Wise, 2003) agree that, throughout its recent history, Peru has experienced significant turmoil, leading to high levels of socioeconomic 
uncertainty and instability. In the early 1990s, the election of Alberto Fujimori led to a series of reforms, including liberalization of trade, privatization of state enterprises and fiscal discipline (Arce, 2005). Between 2002 and 2013, benefitting from macroeconomic policies, a favourable external environment, and structural reforms, Peru experienced faster economic development (World Bank, 2018). While over the years there there has been gradual growth, socioeconomic uncertainty still remains, including through economic dependence. Indeed, the weakening of prices on a global scale, in particular copper, Peru's main export commodity valued at US\$ 38.2 billion in 2017 (World Trade Organization, WTO, 2018), have affected fiscal income, private investment, and consumption (World Bank, 2018).

Although in comparison to the world's leading nations Peruvian tourism has yet to attain status as a key economic activity (Divino \& McAleer, 2010), it nevertheless has experienced growth over the decades. In the mid-1990s, international tourist arrivals started to increase; to a great extent, this upwards trend was due to institutional changes brought forward by government initiatives, and to growing demand for ecotourism and adventure travel. According to the United Nations World Tourism Organization (UNWTO, 2016), Peru's natural resources, fauna and flora, are a major drawcard for many individuals who engage in various forms of tourism, including adventure or ecotourism. A more recent report (UNWTO, 2018) illustrates constant growth in international visitors, from 2.3 million in 2010 and US\$ 2 billion in revenues, to 4.03 million in 2017 and US\$ 3.7 billion in revenues.

More specifically, the World Travel and Tourism Council (WTTC, 2018), provides various facts highlighting the impact of tourism for Peru's economy. First, the contribution of travel and tourism to Peru's gross domestic product (GDP) was US\$ 8.1 billion in 2017, or $3.8 \%$ of the nation's total GDP in the same year. Second, 400,000 jobs or $2.5 \%$ of Peru's total employment were directly supported through tourism. Third, travel and tourism investment in 2017 represented US\$2.2 billion, with projections to continue rising (WTTC, 2018). 
The growing significance of tourism for Peru's economy underscores the value of researching its gastronomic potential as a key complementing factor to the tourism experience. Investigating this key dimension could also bring together aspects of interest for visitors, for instance, the nexus between local culture and cuisine, or even Peru's gastronomic heritage. In the last two decades, there has been a surge in the popularity of Peruvian cuisine (López-Canales, 2019), “exporting Peruvian culture to the world” (García, 2013, p. 505). This phenomenon is also reflected in culinary tourism (Nelson, 2016), and sustainable culinary tourism research (Duarte Alonso, Kok, \& O’Brien, 2017).

While indisputably culinary tourism has emerged as an area of growth in the context of Peru, studies have not explicitly discussed the significance of Peruvian cuisine, for instance, as a tool that projects or conveys a sense of place or enhances socioeconomic development.

Thus, one key objective of the present study is the examination of sense of place in the context of Peruvian cuisine as well as its entrepreneurial potential. This line of research could help identify and highlight stronger links between Peru's foods and cuisine. Furthermore, the findings of the study could help increase awareness of culinary experiences among future visitors worldwide, and ultimately enhance their visiting experience, while learning yet another fundamental aspect of Peruvian culture. This first objective of the research is complemented by a second, where the significance of the local gastronomy is positioned as a tool to address current and future socioeconomic uncertainty. Consequently, the following key research questions (RQs) will be explored:

RQ1: How is Peru's cuisine helping shape a sense of place?

RQ2: How can the local cuisine contribute to alleviating uncertain socioeconomic conditions? 
Complementing the empirical nature of this study's research questions, the insights of entrepreneurial action (McMullen \& Shepherd, 2006; Mitchell \& Shepherd, 2010) will be drawn. Through this theoretical lens, increased understanding can be generated in the context of the role of local cuisine in motivating entrepreneurship (RQ2) in an environment where economic, and other forms of uncertainty are still present. Consequently, an additional question is proposed:

RQ3: To what extent can the theory help broaden the understanding of the main dimensions examined in this study, notably:

a) The significance of local cuisine in creating a sense of place?

b) The contribution of local cuisine in helping deal uncertain socioeconomic conditions?

\section{Literature Review}

Food, gastronomy and tourism

Food and gastronomy are essential aspects of many nations' history, culture, and heritage. As Sormaz et al. (2016) posit, "culinary culture is always the longest-surviving part of a culture and tradition" (p. 725). Within food and gastronomy, food tourism provides an extremely valuable experiential component for travellers. Food tourism includes elements of gastronomy tourism, which is typically associated with haute cuisine and high-end restaurants (Hall, 2019; Povey, 2011), and visitation to food producers, food markets, food events, where a region's attributes in specialist food production are essential factors for travel (Hall and Mitchell, 2001). Food tourism also encompasses such categories as beer, cheese or wine tourism, and overall seeks to contribute to a general understanding regarding what tourists consume, and the infrastructure and experience surrounding it (Hall, 2019). 
Associated with the present research, restaurants are in a strategic position to champion local foods, and bring "a much vaunted authenticity to the experience that the tourism destination delivers to the market" (Presenza and Del Chiappa, 2013, p. 183). In this context, creativity and innovation play fundamental roles. Creativity in as a culinary process entails working on, incubating and development ideas, eventually materialising them (SánchezJofras, and Kuri-Alonso, 2019). Innovation can be illustrated through the development of new food products tailored to the needs of new consumers (Beer et al., 2002), or through the use of local products to prepare typical local dishes, which allow restaurants to enhance their competitiveness (Presenza and Del Chiappa, 2013).

\section{Sense of place}

Shamai (1991) defines sense of place as an umbrella concept encompassing other concepts, such as regional awareness, national identity, or attachment to a place. Haven-Tang and Jones (2005) emphasise the significance of maximising the potential of local foods and drinks, and create a sense of place, which can contribute to uniqueness in visitors' experiences. At the same time, the 'selective customisation' of a destination's distinctive attributes, in this case local products, can have ramifications in the form of economic benefits and differentiation of tourism destinations (Haven-Tan \& Jones, 2005). In presenting various dimensions underlining the role of gastronomy in developing a sense of place, Richards (2014) posits that food has linkages with local landscapes, whereby consumers can literally witness where food originates, provides unique experiences.

Sense of place has been associated with Peru's gastronomy, identity, and culture. For instance, Divino and McAleer (2010) explain that Peruvian cuisine constitutes one way of emphasising its cultural diversity, in addition to other aspects such as its indigenous cultures, primarily mirrored in the architecture (e.g., Machu Picchu). Furthermore, popular media 
sources have progressively emphasised descriptions of foods and drinks, including from the more traditional images of the country's iconic landscapes. One of the intents of these promotional efforts is elevating the image of Peru's gastronomy, through its positioning as a leading culinary destination (Nelson, 2016). Unsurprisingly, culinary tourism is a key segment in promotional activities of Peru's Export and Tourism Promotion Board (Nelson, 2016).

\section{Entrepreneurial action theory}

The links between entrepreneurship, in this case, through the potential of Peru's culinary tourism, as a tool to address or even alleviate socioeconomic merits the consideration of entrepreneurial action as a theoretical framework in this research. Furthermore, the associations between entrepreneurship and entrepreneurial action highlight the importance to define various key terms. For instance, the academic literature proposes various conceptualisations of what constitutes entrepreneurship. Kent, Sexton, and Vesper (2009) define this term as the establishment of new businesses, whereby the creator (the entrepreneur) assumes the role of agent of change, starting industrial growth, with implications for wider cultural change. George and Zahra (2002) postulate that entrepreneurship is a process and an act by which individuals, organisations, regions or even societies recognise "identify and pursue business opportunities to create wealth" (p. 5).

However, the literature also identifies barriers preventing entrepreneurship; one of these is uncertainty, which McMullen and Shepherd (2006) further depict in two streams: level of uncertainty perceived, and willingness to bear uncertainty.

Furthermore, in considering earlier research (Hebert \& Link, 1988; Higgins \& Kruglanski), MacMullen and Shepherd (2006) make two significant points. First, they posit that individuals need to act to become entrepreneurs, and that, alongside with stimulus, acting 
involves motivation and knowledge. Second, they highlight that, through entrepreneurial action, entrepreneurs can both generate and respond to change.

Entrepreneurial action is referred to as behaviour which occurs "in response to a judgemental decision under uncertainty about a possible opportunity for profit” (McMullen \& Shepherd, 2006, p. 134). Entrepreneurial action is contingent upon the extent to which individuals rely on their judgment, and this depends on the level of uncertainty that individuals experience when they are to decide on whether to act (McMullen \& Shepherd, 2006). In essence, entrepreneurial action is related to individuals' willingness to bear uncertainty (McMullen \& Shepherd, 2006). According to Shepherd and Patzelt (2010), several studies, including those conducted by Peredo and Chrisman (2006) or O’Neill, Hershauer and Golden (2009) illustrate that entrepreneurial action can make contributions in sustaining communities. Entrepreneurial action can be manifested through the introduction of products to markets, establishing new organisations or through investments (Klein, 2008).

Two stages depicted in a theoretical framework by McMullen and Shepherd (2006), have been associated with entrepreneurial action. The first, opportunity attention, which refers to third-person opportunity or first-person attention, relates to questions that seek to answer why opportunities are identified and realised in general (Mitchell \& Shepherd, 2010). This stage, which underlines radical uncertainty (McMullen \& Shepherd, 2006), links prior knowledge and motivation in the form of personal strategy. Importantly, this stage is associated with the domain of culinary tourism development.

Nelson's (2016) research based on media articles reveals that Peru's image as a culinary destination is consistent with sources associated to travel enthusiasts' information processing, including experiential marketing. This type of marketing contributes in engaging readers- or potential visitors- resulting in an emotional attachment. Moreover, experiential marketing adds value, and complements the main purposes of travel as well as increases the emerging 
interest in culinary tourism, which is also often associated with native ingredients, culture, or tradition (Nelson, 2016).

Similarly, Duarte Alonso, Kok, and O’Brien (2018) identified the growing interest for Peru's local cuisine among international tourists, the establishment of culinary neighbourhoods, and the increasing experimentation with less known foods to cater for food enthusiasts. In the context of entrepreneurial action theory, these two studies highlight opportunities in general for Peruvian hospitality operations. These contributions also resonate with earlier research conducted in Cordoba, Spain (Sánchez-Cañizares \& López-Guzmán, 2012), which concludes that, despite the existence of global uncertainty, the demand for gastronomy continues to grow.

The second stage brought forward by McMullen and Shepherd (2006), opportunity evaluation, addresses questions of why opportunities are detected and acted upon by individuals in situations of uncertainty. Moreover, as opposed to the opportunity attention stage, in opportunity evaluation, individuals identify opportunities for themselves, and decide "to act on these opportunities in the face of uncertainty through investment and pursuit" (Mitchell \& Shepherd, 2010, p. 140). Autio, Dahlander, and Frederiksen (2013) posit that opportunity evaluation can be operationalised in terms of business planning, and that during this stage individuals identify a specific course of action, such as launching an enterprise to exploit opportunities, and determine whether this exploitation is desirable or feasible. McMullen and Shepherd's (2006) framework illustrates a direct relationship between knowledge in the form of feasibility assessment and motivation, conceptualised as desirability assessment.

"The emphasis of the evaluation stage on an individual as opposed to in general (attention stage) can be transferred into or interpreted within the domains of sense of place and culinary tourism. According to Shamai (1991), sense of place not only emphasises the role of location; 
indeed, location is not sufficient to generate a sense of place. Instead, a deep and long experience of a place, or even involvement in the place, are requirements "to create a sense and attachment to place" (Shamai, 1991, p. 348). A place is part of a larger dimension, whereby meaningful events or actual experiences can be felt, for instance, through hearing, sight, touch, smell or taste (Shamai, 1991). In addition, sense of place consists of belonging, attachment, and commitment to a place (Shamai, 1991). Moreover, the search of perceived real meanings of places, or the discovery of heritages can be interpreted as a response and a desire to secure one's identity amidst constant change and movement (Massey, 1997). In this context, a sense of place based on rootedness can contribute towards an uncomplicated identity (Massey, 1997).

In the field of tourism, Haven-Tang and Jones (2006) explain the significance of a sense of place, in contributing to enhance a destination's attributes, and stress the need for individual businesses to customise selectively this concept. Consequently, sense of place could help maximise distinctive cultural or social characteristics, which in turn can provide unique travel experiences (Haven-Tang \& Jones, 2006). In the area of culinary tourism, Scarpato and Daniele (2003) and Richards (2003) highlight the strong relevance of a sense of place for tourists' gastronomic experiences, which suggest implications for hospitality entrepreneurs. Furthermore, in reviewing cases such as those in the slow food and agritourism sectors, DiGregorio (2017) underlines "the value-creating potential of opportunities for the implementation of place-based business models" (p. 113).

\section{Methodology}

This study contributes to the academic literature, including to the place and destination management literature, in several forms. Fundamentally, by examining the extent to which local cuisine helps shape a sense of place, and how local cuisine contributes to addressing 
uncertain socioeconomic conditions, the study adds to the limited body of knowledge on these dimensions in the context of South America, and specifically in Peru. Indeed, only three studies have recently addressed the significance of gastronomy in this nation (Duarte Alonso et al., 2017, 2018; Nelson, 2016).

According to recent news reports (e.g., Moss, 2017; Tegel, 2016), Peru has become a culinary magnet in the region. Furthermore, the present study relies on data gathered among restaurant owners and managers. Therefore, the unit of analysis, or that confined set of elements that include the object being the focus of the investigation (Gronn, 2002) is represented by the insights of entrepreneurs operating in the hospitality industry.

The study utilises an inductive paradigm and constructivist philosophy. Through considering entrepreneurial action, and by seeking to identify associations between the findings and this theory, the study proposes a framework (Figure 1) to enable better understanding concerning the links between theory, local gastronomy, a destination/place, sense of place, and addressing uncertain socioeconomic conditions. This contribution is in agreement with inductive analysis, an approach based on a researcher's interpretation of mainly "detailed readings of raw data" (Thomas, 2006, p. 238) that are employed to derive themes, concepts, or a model.

Data were collected predominantly through the use of qualitative interviews supported by observations and archival information collected from respondents drawn from the purposive sampling methodology. Patton (2015) defines purposive sampling as the strategic selection of information-rich cases that, given their substance and nature, will add insights to address the examined inquiry question. The selection of information-rich cases, or in this instance, knowledgeable individuals, is also associated with a multicase study approach. Regarding this approach, Stake (2006) posits that single cases can be interesting as they are part of a collection of cases. In addition, cases should be similar, such as selecting a set of teachers, 
and should be examined to ascertain their complexity or situational uniqueness (Stake, 2006). The purposive sampling criteria focused upon firms with owners and/or managers with detailed knowledge of their locality to be information rich cases. Furthermore, potential participants had to be active in Peru's gastronomic scene for five or more years, and as a result, possess an in-depth understanding of the business (involved with the operations, strategic direction or key aspects of running the firm).

Gathering the responses from consolidated businesses whose owners and managers are experienced and knowledgeable provided numerous insightful observations. Selecting knowledgeable individuals is in accord with a constructivist approach, and with purposive sampling. Magoon (1977) explains that the constructivist view chiefly assumes that the 'subjects' to be studied "must at a minimum be considered knowing beings" (p. 652). Moreover, the knowledge of subjects has significant consequences for how actions or behaviour are interpreted (Magoon, 1977). During this initial interview process, participants suggested other neighbouring Cevicherías. This referral of other individuals, which aligns with a snowball sampling technique or sampling (Noy, 2008), resulted in an additional seven interviews, which were compliant with the purposive sampling criteria indicated earlier.

During 2016, preliminary internet searches helped the research team identify 10 Cevicherías, or restaurants specialising in Ceviche, a popular dish consumed in Peru. More specifically, Ceviche consists of raw fish, and one of its key characteristics is the marinating of the raw fish with lime juice (Mathur \& Schaffner, 2013). Ceviche is the most well-known dish in Peru (Pérez Gálvez et al., 2017). Similarly, the restaurants selected also featured other traditional Peruvian dishes in their menus, including 'Papas a la Huancaína' (potatoes served in a spicy cheese sauce), or various seafood dishes, such as the Parihuela (fish and seafood soup), or 'chupe de camarones' (prawns and fish soup). In addition, the restaurants had been part of Peru's gastronomic scene for a number of years. 
A message was sent to the attention of the owners/managers, informing them of the objectives of the study, and making a formal request for the research team to gather data through a face-to-face interview onsite. A positive reply was received from the majority (7) of these firms. Between December of 2016 and early January of 2017, one member of the research team travelled to Lima, Peru; this city was chosen for the data collection mainly as it is reinventing itself as a gastronomy destination (Moss, 2017). Moreover, research has underlined the emergence of Lima in the world of gastronomy. For instance, Pérez Gálvez et al. (2017) posit that Lima is already "considered as one of the main gastronomic leaders of the world" (p. 254). Along these lines, García (2013) and Higgins (2005) explain the efforts and desires within Lima's gastronomy scene to position this city as South America's culinary capital. García (2012) also identifies the growing popularity and international appeal of Mistura, a gastronomic festival organised in this city. Furthermore, Peru's signature dish, Ceviche enjoys strong preference among international visitors (Gonzaga et al., 2009).

During the interviews, basic demographic data were gathered regarding participants and their restaurants (Table 1); subsequently two central questions were asked:

To what extent does the local gastronomy contribute to:

a) Emphasise a sense of place?

b) Deal with existing uncertain conditions, for instance, Peru's existing socioeconomic uncertainty?

These questions were developed through readings and interpretations of recent tourism research conducted in Peru (Duarte Alonso et al., 2017; 2018; Nelson, 2016). In addition contributions emphasising sense of place, place branding, and socioeconomic development in culinary tourism were also considered (e.g., Haven-Tang \& Jones, 2006; Lee, Wall, \& 
Kovacs, 2015; Richards, 2003; Scarpato \& Daniele, 2003; Smith, 2015; Tsai, 2016).

The semi-structured interviews lasted on average one hour and fifteen minutes and were audio recorded with participants' consent. These were complemented with written information from materials such as brochures and restaurant websites.

In line with Hsieh and Shannon (2005) and Schreier (2014), qualitative content analysis was employed, essentially, to interpret, identify, assign and classify categories and themes emerging from the data. The approach was applied to identify consistent and prevalent issues that arose from the different datasets drawn from interview transcripts, archival information and observations. Furthermore, the approach allowed for triangulation of data drawn from multiple sources, thus enhancing overall validity and reliability of findings. Nvivo version 12 was utilised in the coding process identifying recurrent themes and providing robust indication of the different issues within the datasets. The results section discusses the triangulated themes and issues data from the semi-structured interviews, observations and archival data. However, in view of the low number of participants, the overall generalisability of the findings may be limited and must be considered with caution.

\section{Basic demographic characteristics: Participants and firms}

Table 1 indicates that the majority of participants were owners of the Cevichería. Eight had at least one decade of experience in the hospitality industry. Among them one (P14) has gained international reputation for his pioneering work raising the profile of Peruvian cuisine. Similarly, P4 has extensive experience as a restaurateur and as one of Peru's leading authorities in the Peruvian beverage Pisco, while P6 has written three books on Peru's cuisine, and P3 has developed a craft brewing business alongside the restaurant. Finally, males composed the large majority of participants. 
Table 1 Here

\section{Results and Discussion}

RQ1: How Peru's cuisine helps shape a sense of place

Participants' perceptions unequivocally emphasised the significance of a sense of place in the context of local gastronomy in various ways, such as in their passion for local dishes and their willingness to widen awareness of these. These insights also strongly adhere with entrepreneurial action, notably, with opportunity attention, which is associated with questions of why opportunities are spotted and exploited in general terms (Mitchell \& Shepherd, 2010). Furthermore, opportunity attention emphasises motivation and prior knowledge through individuals' strategy (McMullen \& Shepherd, 2006). The links between these theoretical insights and the study's findings were manifested in various triangulated themes within the dataset. For example, part of the conceptualisation of a sense of place, including national identity (Shamai, 1991), were demonstrated through the perceived historic and traditional significance of Peru's cuisine:

P3: “... slowly Peruvians are starting to gain pride due to the growing importance and relevance of some products: Pisco sour, Ceviche, Marinera..." P4: The Ceviche is Peru's registered mark. While there is Ceviche along the Pacific coast... The most renown is the Peruvian Ceviche.

P6: The National Institute of Culture declared Ceviche part of Peru's gastronomic patrimony... You can make ceviche with whatever ingredients, but making Ceviche Peruvian style, the true ceviche, is an art...

In line with research by Haven-Tan and Jones (2005), sense of place was also identified 
through efforts to position local of foods and beverages (P5): Right now, the Aguaymanto [Cape gooseberry, original from Peru] has been a boom, and it is used in ice-creams... Associated with this comment, P6 indicated the richness of Peruvian products and their potential for raising the profile of Peruvian cuisine further, thus, further reflecting pride and national identity: "Peru is blessed because it has many microclimates and can produce fruits and vegetables. We need to develop our gastronomy much more."

Similarly, comments acknowledged other forms of positioning Peru's gastronomy and cuisine, namely, expanding knowledge internationally through collaborative efforts among Peruvian restaurateurs. These perceptions, which are illustrated in Table 2, were also echoed by additional observation (P5): "We are part of the Peru Brand [Marca Perú], and within this association we usually travel to make Peruvian gastronomy more popular. We are around 30 Cevicherías and, together, we travel to culinary events in Latin America."

Further drawing on the work of Haven-Tan and Jones (2005), sense of place became apparent through the increasing awareness, and growing popularity of Peruvian cuisine among international visitors. From an entrepreneurial perspective, and as the following comments highlight, by emphasising sense of place through culinary and regional identity and awareness, opportunities could be created and exploited for the hospitality and tourism industries, with resulting impacts on Peru's economy:

P2: I was in Chile last week and on the flight I saw three couples who were engaged in a conversation and people asked if they were coming to live in Peru. They responded that they were visiting because of the food.

P7: “We receive numerous international guests... some who already live here, others who are visiting. Some have come expressly because of positive word-ofmouth they received from others, and the majority want to try Ceviche and 
seafood dishes."

Table 2 Here

While overall participants' insights were associated with the opportunity stage, the following insights place emphasis more so upon the evaluation stage, in that individuals identify and act on opportunities in light of uncertainty, namely through pursuit and investment (Mitchell \& Shepherd, 2010). In times when other competitors were moving away from the uniqueness of typical dishes, $\mathrm{P} 8$ was avoiding such changes, thereby carving a niche based on culinary sense of place: We have maintained a traditional menu... we have been successful because nowadays many restaurateurs are moving to fusion or other innovative menus, and as a result, restaurateurs offering traditional cuisine are becoming rarer.

In their position as restaurant manager holding a stake of its ownership, and as owner for over 30 years, two participants recognised the traditional culture that contributed to building the foundation of local cuisine. Moreover, the process in which dishes developed, which was perceived as stemming from humble family environments, and therefore related to a sense of place, emerged as a critical element in positioning Peru's gastronomy:

P9: We are trying to understand how the mothers [from earlier generations] became inspired, and managed to create foods to feed their children... transforming these basic, frugal foods into something delicious, and that now has become part of our gastronomic culture...

P14: Gastronomy in Peru is very traditional; it is a family tradition, which is much stronger than that of other countries that did not experience the social problems of Peru. 
At the same time, there was an ongoing process of growth, with future hospitality professionals gaining skills and experience (P10): "Having...large numbers of young people currently involved in culinary arts is going to show us to the world, and to ourselves, that we can keep growing.” This generational movement could have key implications. Indeed, reinforcing perceptions of a sense of place through the continuation of efforts to maintain local cuisine could result in enhanced experiences for local and international consumers, further contributing to destination image. The above findings again reveal associations with the stage of opportunity attention, acknowledging future opportunities for Peru's gastronomy through generational renewal.

The points and perspectives provided by the above participants are also partly in agreement with research emphasising the role that cuisine and food tourism play in reinforcing local identity. For instance, Everett and Aitchison's (2008) investigation among restaurateurs in Cornwall, England, revealed a correlation between stronger levels of interest in food tourism and development and retention of regional identity. Earlier, Bessière (1998) highlights the role of gastronomy as an identity marker of a region, helping generate a feeling of belonging to a specific area. For example, the gastronomic heritage of a rural area is strongly associated with such cultural elements as peasant identity, or particular production or consumption habits (Bessière, 1998).

\section{RQ2: Local cuisine contribution to dealing with uncertain socioeconomic conditions}

The interview data strongly suggest the significant potential for the local cuisine to become a tool that generates wealth amidst uncertain socioeconomic conditions. First, the previous comments regarding the significance of a sense of place were complemented and strengthened by those illustrating respondents' belief that the local cuisine could become a 
key driver of development. The triangulated findings reveal four key ways to achieve such objective, with increasing knowledge of Peru's cuisine and developing infrastructure being the predominant ones (Table 3). In addition, and as the following selected comments demonstrate, there is conviction and certainty that local cuisine could deliver positive results:

P1: There is a growing phenomenon of people taking Peruvian cuisine to the countries where they live, and the local consumers are responding very positively to this, to them, new food. In various Latin American countries, Peruvian cuisine is the 'hook' drawing patrons to restaurants.

P2: Peru is becoming a gastronomic destination/pilgrimage...Today, gastronomy is already big business...

These perceptions are in accord with Kivela and Crotts (2006), who emphasise the significance of gastronomy as a key element in the process of developing niche destinations and travel. The aspect of pilgrimage noted by P13 is also related to Kivela and Crotts's (2006) research. Indeed, these authors found not only that gastronomy is a major contributor of how visitors experience a destination, but also, and importantly, that some visitors are prepared to repeat their travel to experience the unique local gastronomy.

An additional aspect of certainty was revealed, notably, in that several restaurateurs planned or acknowledged that expansion was already a fact, not only locally, thereby helping develop infrastructure, but also internationally. This finding, which is further illustrated in the following comments, clearly and strongly associates with the opportunity evaluation stage (McMullen \& Shepherd, 2006), whereby the entrepreneurs are prepared to bear uncertainty while identifying opportunities for themselves, including by making necessary investments (Mitchell \& Shepherd, 2010): 
P7: According to our plans, I hope to open a second restaurant in the San Isidro neighbourhood... We are interested in organic growth, growing with our own people...

P10: For the last 4 years, we have been in the list of the 50 best restaurants of Latin America... this company has presence in various countries...

P13: We are preparing a business plan, and we are looking at... which products are needed to be exported from Peru... there is a very large Latino community in the United States.

Table 3 Here

While Peru experienced economic growth over the last decades, for instance, between 2002 and 2013 (World Bank, 2018), it nevertheless continues to experience uncertainty in different fronts. As previously mentioned, the country is vulnerable to the swings of international commodity prices (World Bank, 2018). At the same time, the extent of Peru's informal economy is substantial; as much as $72 \%$ of employment is generated informally across the nation (National Institute of Statistics, INEI, 2016), which has implications, including for infrastructure (less taxes collected), protection of labour and businesses adhering to formal structures. In this context, P11 referred to previous events and the promising developments that were occurring around the development of local gastronomy: "In the 1980s, we experienced political violence, in the 1990s, we had a dictatorship, in the 2000, we had a very imperfect democracy, but we witnessed a bit of an economic bonanza. In such a fragmented, disorganised country, suddenly the gastronomic phenomenon emerged... Gastronomy is therefore extremely important for Peru; again, it gave us identity." This 
comment was echoed by that of $\mathrm{P} 2$, who stressed the traditional value of local cuisine, alongside its strong links with place and people: "Our potential is tied to our history. This history is reflected in many dishes... Therefore, there is a lot of culture in a dish."

Again, as these comments reveal, the elements of a sense of place, tradition, and simplicity (humbleness) could contribute to a strong culinary foundation. Furthermore, the operationalisation of a sense of place through local cuisine and culinary tourism could provide benefits at a firm (individual) level, as well as at a general level (hospitality/restaurant industry). Another way in which these notions became operationalised was the establishment of culinary events which, like the Fair of Gastronomy 'Mistura', which at the time of the study was in its fifth edition, were drawing food enthusiasts and contributing to the rise of culinary tourism (P4). Enhancing professionalism and providing human development, while also minimising the effects of an informal economy, was yet another form in which local cuisine, and more precisely local hospitality entrepreneurs, can address uncertain socioeconomic conditions. Several participants (P1, P3, P4, P12, P14) acknowledged volunteering or investing and providing opportunities to local youth in improving their skills, equipping them with the tools to further their career in the hospitality industry. As P6 explained: “...we have a good group of people, very engaged and well trained... For example, the youngsters who start as helpers cover for the waiting staff. They gradually learn the skills of the job and then are promoted... they came without any knowledge of this business, and we gave them an opportunity to progress professionally."

\section{RQ3: The applicability of the proposed framework}

In accord with Thomas (2006), and Elo and Kingäs (2007), both the chosen inductive approach and content analysis contributed to the development of a theoretical framework (Figure 1). Payne (2018) defines theory as "a simplification of reality, and an attempt to 
parsimoniously explain some relevant components of a phenomenon” (p. 171). In essence, theory helps in classifying, understanding and predicting relationships, as well as guiding future research (2018). Aligned with this definition, the proposed framework depicts relationships between the themes under examination and the tenets of entrepreneurial action (McMullen \& Shepherd, 2006; Mitchell \& Shepherd, 2010) to explain the phenomena (dimensions) under investigation. The place or destination, tourism, culinary tourism, socioeconomic development and uncertainty are suggested as interrelated. In this study, opportunity attention was partly related to RQ1, for instance, in that a sense of place, predominantly based upon four areas (Table 1), including focus on a national dish (Ceviche), products and dishes that represent national price, or expanding the image of Peruvian gastronomy internationally, underlines opportunities in general.

Furthermore, in the context of dealing with uncertain socioeconomic conditions (RQ2), opportunity attention complements opportunity attention. Indeed, the identified ways to deal with uncertainty (Table 3), specifically, by means of incremental knowledge of local cuisine and/or food tourism and developing infrastructure and professionalism, can provide benefits to Peru's hospitality/tourism industry in general as well as to individual operators. In this context, the aspect of 'certainty in uncertainty' emerged from various comments, with participants exhibiting confidence in the potential of local gastronomy to become an even more significant phenomenon.

Moreover, the intention to expand internationally, 'exporting' Peruvian cuisine through franchising arrangements, which aligns with opportunity evaluation, further supported the notion of certainty and confidence in the local cuisine as a tool for socioeconomic development. In the end, addressing opportunity attention and evaluation, coupled with the identified sense of confidence highlights various implications, for instance, in supporting the further achievement of culinary tourism development, with spillovers for the destination, 
including for its tourism and socioeconomic development. Thus, the consideration of entrepreneurial action theory can contribute to a more in-depth analysis and to valuable insights concerning the significance of sense of place through gastronomy and culinary tourism, as well as with dealing with uncertain socioeconomic conditions.

\section{Conclusions}

While academic research focusing on local cuisines has grown exponentially, many knowledge gaps remain unaddressed. For example, despite the growing international reputation of emerging gastronomic destinations, notably, Peru, still relatively little is known about how cuisine contributes to reinforcing or projecting a sense of place. In addition, there is limited knowledge concerning the significance of Peruvian cuisine as a tool for socioeconomic development. In considering entrepreneurial action theory, as well as by examining how Peruvian cuisine contributes to a) shaping a sense of place, and to 2) dealing with uncertain socioeconomic conditions, the present research addressed these gaps.

The results of the study imply that in times of socioeconomic uncertainty, a clear and viable approach as well as strong belief in the niche that has been identified, would enable success. In the case of Peru, the strong sense of identity and place, alongside pride and uniqueness of its local produce affords a suitable avenue to ensure business viability during socioeconomic uncertainty. This notion is particularly useful in the context of entrepreneurial action and contributes not only to dealing with difficulties in the external environment, but also to explaining how entrepreneurial attention and evaluation require a strong sense of confidence in the values they believe in. Therefore, these findings are not limited to the context of Peru's cuisine or sense of place; instead, they can be useful in providing guidance to emerging or developing culinary destinations. 


\section{Implications}

Various implications should be considered. Theoretically, the study has extended understanding of entrepreneurial action theory and its applicability in different contexts. For example, the paper suggests the inherent inter-relatedness between entrepreneurial action and the notion of a sense of place (opportunity attention), where entrepreneurial opportunity and the locality of a country's gastronomy are interlinked. Furthermore, the results highlight the potential value that arises out of locality, not only in enhancing national pride, or preserving culinary ways, but also as a means for businesses to excel, positioning the national gastronomy internationally.

In this context, the findings signpost the importance of being steadfast, as well as having clarity in uncertain socioeconomic conditions (opportunity evaluation), further emphasising the value of applying entrepreneurial action theory. Various stakeholders could therefore benefit from considering the proposed model (Figure 1) which emanates from entrepreneurial action theory. At a government level, agencies engaged in business and tourism development could consider the two stages of entrepreneurial action as a means to understand the benefits accrued from maximising the value of local gastronomy to reduce socioeconomic uncertainty, and ultimately enhance the destination's image. Similarly, these considerations apply to business owners/managers, and hospitality and tourism associations in their efforts to develop a destination's profile.

From a practical perspective, the empirical analysis demonstrates that various stakeholders, including those involved in gastronomy, tourism, or in policy development can play a critical role in nurturing and fostering a sense of place, especially when a niche or unique opportunity arises. Moreover, the realisation of these efforts could be strengthened through funding or infrastructure building. Similarly, careful selection of protectionist approaches to safeguard the value of 'local', should be considered. As suggested by Haven- 
Tang and Jones (2006), there is nonetheless a need to customise selectively.

Moreover, given the nature of focusing on local supplies and a strong pride in what is from the area, there is also much socioeconomic impact to be delivered to the community. The international impact, awareness and recognition of a locality and its traditions further provides different income streams.

The study also signposts useful considerations to engage communities potentially during times of socioeconomic uncertainty, suggesting focus should be placed on opportunities that are on their doorstep rather than looking afar. While the focus is on Peru, a country which has experienced significant turmoil, the results could be equally applicable to more developed culinary destinations, where socioeconomic uncertainty exists in different guises, including through the impacts of economic downturns or Brexit.

\section{Limitations and Future Research}

The study has focused upon only 14 business owners and managers, and primarily on firms operating in the hospitality sector. These aspects must be considered in the generalisability of the results, and in the overall applicability of the framework to the wider context. In addition, it is important to bear in mind the nature of qualitative research and the ability to generalise findings. Future studies could not only seek to replicate the findings to further bolster its reliability and validity but may also utilise more quantitative methods to test the notions put forward by this paper. This line of research could also entail a larger sample size and potential utilise different sampling methodologies to examine the population. Moreover, there are avenues to examine other business types and indeed countries where socioeconomic uncertainty and turbulence exists to identify if the convictions and prominence of a sense of place as revealed by this study is equally prevalent.

Future studies could undertake detailed qualitative research on consumers and tourists 
to examine their experiences and if the image of Ceviche as a national Peruvian dish is translated in their taste and travels. This could provide rich understanding in examining Ceviche- or other Peruvian dishes- and their appropriateness and draw to create a sense of place from the point-of-view end-user, providing valuable insight on the overall effect of cuisine and travel as part of the identity of a locality. Studies here could also reveal the benefits gained by touristic offerings that match a visitor's perceived notion of an intended travel destination.

\section{References}

Arce, M. (2005). Market reform in society: Post-crisis politics and economic change in authoritarian Peru. University Park, PA: The Pennsylvania State University Press.

Autio, E., Dahlander, L., \& Frederiksen, L. (2013). Information exposure, opportunity evaluation, and entrepreneurial action: An investigation of an online user community. Academy of Management Journal, 56(5), 1348-1371.

Babb, F. (2011). The tourism encounter: Fashioning Latin American nations and histories. Stanford, CA: Stanford University Press.

Beer, S., Edwards, J., Fernandes, C., \& Sampaio, F. (2002). Regional food cultures: integral to the rural tourism product? In A. Hjalager and G. Richards (eds.), Tourism and gastronomy (pp. 207-233). London, UK: Routledge.

Bessière, J. (1998). Local development and heritage: traditional food and cuisine as tourist attractions in rural areas. Sociologia Ruralis, 38(1), 21-34.

Desforges, L. (2000). State tourism institutions and neo-liberal development: A case study of Peru. Tourism Geographies, 2(2), 177-192.

Di Gregorio, D. (2017). Place-based business models for resilient local economies: Cases 
from Italian slow food, agritourism and the albergo diffuso. Journal of Enterprising Communities: People and Places in the Global Economy. 11(1), 113-128.

Divino, J.A., \& McAleer, M. (2010). Modelling and forecasting daily international mass tourism to Peru. Tourism Management, 31(6), 846-854.

Duarte Alonso, A., Kok, S., \& O’Brien, S. (2017). Sustainable culinary tourism and Cevicherías: a stakeholder and social practice approach. Journal of Sustainable Tourism, 26(5), 812-831.

Duarte Alonso, A., Kok, S.K., \& O’Brien, S. (2018). "We are only scratching the surface" A resource-based and dynamic capabilities approach in the context of culinary tourism development. Tourism and Recreation Research, 43(4), 511-526.

Elo, S., \& Kyngäs, H. (2008). The qualitative content analysis process. Journal of Advanced Nursing, 62(1), 107-115.

Everett, S., \& Aitchison, C. (2008). The role of food tourism in sustaining regional identity: A case study of Cornwall, South West England. Journal of Sustainable Tourism, 16(2), 150-167.

Gálvez, J.C.P., López-Guzmán, T., Buiza, F.C., \& Medina-Viruel, M.J. (2017). Gastronomy as an element of attraction in a tourist destination: the case of Lima, Peru. Journal of Ethnic Foods, 4(4), 254-261.

García, M.E. (2013). The taste of conquest: colonialism, cosmopolitics, and the dark side of Peru's gastronomic boom. The Journal of Latin American and Caribbean Anthropology, 18(3), 505-524.

George, G. \& Zahra, S.A. (2002). Culture and its consequences for entrepreneurship. Entrepreneurship Theory and Practice, 26(4), 5-8.

Gonzaga, V.E., Lescano, A.G., Huamán, A.A., Salmón-Mulanovich, G., \& Blazes, D.L. (2009). Histamine levels in fish from markets in Lima, Peru. Journal of Food 
Protection, 72(5), 1112-1115.

Gronn, P. (2002). Distributed leadership as a unit of analysis. The Leadership Quarterly, 13(4), 423-451.

Hall, C. M. (2019). Improving the recipe for culinary and food tourism? The need for a new menu. Tourism Recreation Research, forthcoming.

Hall, C. M., \& Mitchell, R. (2001). Wine and food tourism. In N. Douglas, N. Douglas, \& R. Derrett (Eds.), Special interest tourism: Context and cases (pp. 307-329). New York: John Wiley.

Haven-Tang, C., \& Jones, E. (2006). Using local food and drink to differentiate tourism destinations through a sense of place: A story from Wales-dining at Monmouthshire's great table. Journal of Culinary Science and Technology, 4(4), 69-86.

Higgins, J. (2005). Lima: A cultural and literary history, Oxford, UK: Signal Books.

Hsieh, H.F. \& Shannon, S.E. (2005). Three approaches to qualitative content analysis. Qualitative Health Research, 15(9), 1277-1288.

INEI (2018). Rate of informality among men and women according to geographic location.

Available at: https://www.inei.gob.pe/buscador/?tbusqueda=informalidad

Kelly, J.M. (2003). Counting on the past or investing in the future? Economic and political accountability in Fujimori's Peru. The Journal of Politics, 65(3), 864-880.

Kent, C.A., Sexton, D.L. \& Vesper, K.H. (1982). Encyclopedia of entrepreneurship, Englewood Cliffs, NJ: Prentice-Hall.

Kivela, J. \& Crotts, J.C. (2006). Tourism and gastronomy: Gastronomy's influence on how tourists experience a destination. Journal of Hospitality and Tourism Research, 30(3), $354-377$.

Klein, P.G. (2008). Opportunity discovery, entrepreneurial action, and economic Organization. Strategic Entrepreneurship Journal, 2(3), 175-190. 
Lee, A.H., Wall, G., \& Kovacs, J. F. (2015). Creative food clusters and rural development through place branding: Culinary tourism initiatives in Stratford and Muskoka, Ontario, Canada. Journal of Rural Studies, 39, 133-144.

López-Canales, J. (2019). Peru on a Plate. Coloniality and modernity in Peru's high-end cuisine. Anthropology of Food, (14).

Magoon, A.J. (1977). Constructivist approaches in educational research. Review of Educational Research, 47(4), 651-693.

Massey, D. (1997). A global sense of place. In A. Gray and J. McGuigan, Studying culture (pp. 232-240). London, UK: Edward Arnold.

Mathur, P. \& Schaffner, D.W. (2013). Effect of lime juice on Vibrio parahaemolyticus and Salmonella enterica inactivation during the preparation of the raw fish dish ceviche. Journal of Food Protection, 76(6), 1027-1030.

McMullen, J.S. \& Shepherd, D.A. (2006). Entrepreneurial action and the role of uncertainty in the theory of the entrepreneur. Academy of Management Review, 31(1), $132-152$.

Milliken, F.J. (1987). Three types of perceived uncertainty about the environment: State, effect, and response uncertainty. Academy of Management Review, 12(1), 133-143.

Mitchell, J.R. \& Shepherd, D.A. (2010). To thine own self be true: Images of self, images of opportunity, and entrepreneurial action. Journal of Business Venturing, 25(1), 138154.

Moss, C. (2017). How Lima shed its dangerous reputation to become South America's greatest city for food. The Telegraph online, available at: https://www.telegraph.co.uk/travel/destinations/southamerica/peru/articles/peru-food-guide-best-places-to-eat/.

Nelson, V. (2016). Peru's image as a culinary destination. Journal of Cultural Geography, 
33(2), 208-228.

Noy, C. (2008). Sampling knowledge: The hermeneutics of snowball sampling in qualitative Research. International Journal of Social Research Methodology, 11(4), 327-344.

O’Neill, G.B., Hershauer, J.C., \& Golden, J.S. (2009). The cultural context of sustainability Entrepreneurship. Greener Management International, 55, 33-46.

Patton, M.Q. (1990). Qualitative research and evaluation methods (4 ${ }^{\text {th }}$ ed.), Los Angeles, CA, Sage Publications, Inc.

Payne, G.T. (2018). Reflections on family business research: Considering domains and theory. Family Business Research, 31(2), 167-175.

Peredo, A.M. \& Chrisman, J.J. (2006). Toward a theory of community-based Enterprise. Academy of Management Review, 31(2), 309-328.

Povey, G. (2011). Gastronomy and tourism. In P. Robinson, S. Heitmann and P. U. C. Dieke (eds.), Research Themes for Tourism, UK and USA (pp. 233-248). Wallingford, UK: CABI.

Presenza, A., \& Del Chiappa, G. (2013). Entrepreneurial strategies in leveraging food as a tourist resource: a cross-regional analysis in Italy. Journal of Heritage Tourism, 8(23), 182-192.

Richards, G. (2014). The role of gastronomy in tourism development. Presentation to the Fourth International Congress on Noble Houses: A Heritage for the Future, Tilburg University, The Netherlands.

Richards, G. (2002). Gastronomy: and essential ingredient in tourism production and consumption?, In A-M. Hjalager and G. Richards (eds.), Tourism gastronomy (pp. 120), London, UK: Routledge.

Sánchez-Cañizares, S.M. \& López-Guzmán, T. (2012). Gastronomy as a tourism resource: profile of the culinary tourist. Current Issues in Tourism, 15(3), 229-245. 
Sánchez-Jofras, J. F., \& Kuri-Alonso, I. (2019). Education and innovation in gastronomy: A case study of culinary art school in Tijuana, Mexico. In M. Peris-Ortiz, M.R. CabreraFlores, and A.S. Santoyo (eds.), Cultural and Creative Industries (pp. 101-119). Cham, Switzerland: Springer.

Scarpato, R. \& Daniele, R. (2003). New global cuisine: Tourism, authenticity and sense of place in postmodem gastronomy. In Hall, C.M., Sharples, L., Mitchell, R., Macionis, N. and Cambourne, B. (eds.) Food tourism around the world: Development, management and markets (pp. 296-313), Oxford, UK. Butterworth-Heinemann.

Schreier, M. (2014). Qualitative content analysis. In U. Flick (ed.), The Sage Handbook of Qualitative Data Analysis (pp. 170-183), London, UK: Sage.

Shamai, S. (1991). Sense of place: An empirical measurement. Geoforum, 22(3), 347-358.

Shepherd, D.A. \& Patzelt, H. (2011). The new field of sustainable entrepreneurship: Studying entrepreneurial action linking "what is to be sustained" with "what is to be developed. Entrepreneurship Theory and Practice, 35(1), 137-163.

Smith, S. (2015). A sense of place: Place, culture and tourism. Tourism Recreation Research, 40(2), 220-233.

Sormaz, U., Akmese, H., Gunes, E., \& Aras, S. (2016). Gastronomy in tourism. Procedia Economics and Finance, 39, 725-730.

Stake, R.E. (2006). Multiple case study analysis. New York, The Guildford Press.

Tegel, S. (2016). Why Peru's gastronomy is a bigger draw for tourists than the Incas. The Independent online, available at: https://www.independent.co.uk/news/world/americas/why-perus-gastronomy-is-abigger-draw-for-tourists-than-the-incas-a6805026.html.

Thomas, D.R. (2006). A general inductive approach for analyzing qualitative evaluation Data. American Journal of Evaluation, 27(2), 237-246. 
Tsai, C.T. (2016). Memorable tourist experiences and place attachment when consuming local food. International Journal of Tourism Research, 18(6), 536-548.

UNWTO (2018). UNWTO Tourism Highlights 2018 edition. Aailable at: https://www.e-unwto.org/doi/pdf/10.18111/9789284419876.

UNWTO (2016). Tourism and culture partnership in Peru - Models for collaboration between tourism, culture and community. Available at: https://www.e-unwto.org/doi/pdf/10.18111/9789284417599.

Wise, C. (2003). Reinventing the state: Economic strategy and institutional change in Peru, Ann Arbor, MI: University of Michigan Press.

World Bank (2018). The World Bank in Peru - Overview, available at: http://www.worldbank.org/en/country/peru/overview.

WTO (2018). Peru - Non-agricultural products. Available at: http://stat.wto.org/CountryProfile/WSDBCountryPFView.aspx?Language=S\&Countr $\mathrm{y}=\mathrm{PE}$.

WTTC (2018). Peru - 2018 Annual research: Key facts. Available at:

https://www.wttc.org/-/media/files/reports/economic-impact-research/countries2018/peru2018.pdf. 